\title{
Results of Retrograde K-Wire Fixation in Diaphyseal Fractures of Forearm in Children
}

\author{
Shrestha $\mathrm{DK}^{1}$, Karki $\mathrm{P}^{2}$, Lakhanpal VP ${ }^{3}$, Mishra $\mathrm{SM}^{4}$
}

\begin{abstract}
Background: Diaphyseal fractures of forearm is the third most common fracture in children. Majority of these fractures can be treated with close reduction and cast immobilization due to the growth potential of the immature skeletal. But in elder age group Intramedullary $\mathrm{K}$ wire fixation through retrograde approach is the most invasive and less complicated procedure to ensure the prevention of deformity and restore the functions. Aim: To evaluate the effectiveness of the treatment of diaphyseal fractures of forearm in children with intramedullary $\mathrm{K}$ wire fixation through retrograde approach and look for short term and immediate results. Methodology: This was a prospective observational hospital based study carried out in Nepalgunj Medical College Teaching Hospital from January 2012 to December 2013, in children between 5-15 years with K wires for diaphyseal fractures of forearm through retrograde approach which was followed up for 12 months. All patients underwent close reduction and intramedullary $\mathrm{K}$ wire fixation retrogradely. At 6, 12 and 48 weeks; range of motion and tenderness were looked for. Results: There were 32 patients in the study with average age of 10.41 years for male and 10.21 years for female. Average time for union was 7.3 weeks. There were no nonunions and malunions in follow ups. At 6 months all had full range of motion without any complications. Conclusion: Operative treatment with $\mathrm{K}$ wires through retrograde approach for diaphyseal fractures of forearm is an invasive procedure for less complications, patient's comfort and early range of motion.
\end{abstract}

Key Words: Diaphyseal fractures of forearm, retrograde K wire fixation

\section{INTRODUCTION}

Diaphyseal fractures of forearm in children are the common paeditric traumatic fractures which comprises six to ten percent of all paeditric fractures ${ }^{1,2,3,4}$. and are among the most challenging to the orthopaedic surgeon because of their treatment complexity and frequent complications $\mathrm{s}^{4,5,6}$.

The peak incidence corresponds to the peak velocity of growth when the bone is weakest owing to a dissociation between bone growth and mineralization. They may occur in distal third, middle third or proximal third of diaphysis. They are more common in the middle third ${ }^{5,6,7,8}$. They may be closed, may be displaced or undisplaced. The displacements encountered are angulations, rotation and overriding depending upon the nature, amount of force and mechanism of injury. These displacements result in deformities more frequently because of the difficulty in reducing and maintaining the reduction of two parallel bones in the presence of the pronating and supinating muscles that have angulating and rotational influences.

1. Dr. Dinesh Kumar Shrestha

2. Dr. Prateek Karki

3. Prof. V. P. Lakhanpal

4. Prof. S. M. Mishra

Address for correspondence:

Dr. Dinesh Kumar Shrestha

Department of Orthopedics

Nepalgunj Medical College Teaching Hospital,

Kohalpur, Banke, Nepal

Email: dr_dineshstha@yahoo.com
A practical classification of shaft fractures of the forearm in the paediatric population recognizes the existence of two bones, three levels (the proximal, middle and distal thirds) and four fracture patterns i.e., plastic deformation, greenstick, complete and communited ${ }^{8}$.

The goal of treatment of diaphyseal fractures of forearm in children is to regain length, apposition, rotational alignment of fragments and to allow the fracture to unit in desirable position ${ }^{9}$. The majority of these fractures can be treated well with close reduction and cast immobilization due to the unique property of the growth potential of the immature skeletal. Beside this, with advancement in anaesthesia and in antisepsis and the development of inert implants paediatric forearm fracture treatment has changed towards operative to ensure the prevention of deformity and restore the functions.

\section{MATERIALS AND METHODS}

The present study was a prospective observational study conducted in Nepalgunj Medical College Teaching Hospital (NGMCTH) Kohalpur from January 2012 to December 2013. All paediatric patient (5-15 years of age) attending to the Orthopaedic outpatient department (OPD) or emergency (ER) department with diaphyseal fracture of forearm were included, which comprises of 32 patients. There were $20(62.5 \%)$ boys and $12(37.5 \%)$ girls. Eighteen $(56.25 \%)$ patients had fracture on the left and Fourteen $(43.75 \%)$ had on the right forearm. The study strictly adhered to the tenets of declaration of Helsinki. An ethical informed consent too was taken from the patient party and NGMCTH to carry the study. 
After primary management in the ER, examination of the patients was carried out by 2 orthopaedic surgeons. Two view $x$ rays were done including antero-posterior and lateral. Patients with displaced closed and open diaphyseal fractures of both bones of forearm between the age of 5-15 years, who arrived within seven days of injury were included in the study. Patients with Galaezzi's and Monteggia's fracture dislocation, radial head fractures, isolated single bone fracture of forearm and patients losing in follow ups were excluded from the study.

After the clinical diagnosis of diaphyseal fracture of both bone of forearm, first aid long arm plaster of paris slab were applied in the position of deformity and relevant routine investigations was done and after dressing the open wound if any, patient were admitted in the orthopaedic ward with limb elevation.

\section{OPERATIVE TECHNIQUE}

All surgeries were performed by the authors under tourniquet control and under all aseptic precautions a small longitudinal incision was made over dorsolateral aspect of radius and over dorsomedial aspect of ulna, about one centimeter proximal to the distal physis of these bones. The portal of entry was made by bone awl, protecting superficial radial nerve and dorsal tendons $\mathrm{s}^{10}$.Similarly portal in ulna was also made by bone awl about one centimeter proximal to the physis in the interval between extensor carpi ulnaris and flexor carpi ulnaris tendons $\mathrm{s}^{11}$. A hole was deepened first perpendicularly and then obliquely towards the elbow ${ }^{12}$ Breach in the cortex was ascertained by the feel of loss of resistance and oozing of marrow and the negotiation of medullary canal was confirmed under image intensifier. Depending on the size of medullary cavity, a well fitting round $316 \mathrm{~L}$ stainless steel $\mathrm{K}$ - wire with a diameter of about two third of diameter of medullary canal as described by Ali et $\mathrm{al}^{13}$, Cellebi et $\mathrm{Al}^{14}$ and $\mathrm{Ge}$ et $\mathrm{al}^{15}$ were chosen. The range of size of nail used was 2-3 $\mathrm{mm}$ in diameter and the advancing blunt end of K-wire was bent at 30 degree to avoid perforation of the opposite cortex and was inserted using T-handle ${ }^{12}$. Reduction was done by external manipulation and advanced into the proximal fragment. Then the K-wire was bent and cut $5-10 \mathrm{~mm}$ from the bone to prevent its migration and was buried under the soft tissue, skin was closed and above elbow slab was applied and limb was kept elevated. Active finger movements were started after the patient woke up. In the absence of wound infection and neurovascular complications, patients were discharged on an average hospital stay of 3-5 days.

Subsequent follow up were done first at 2 weeks, stitches were removed. Second follow up was done at 6 weeks, at that time slab were removed. Third follow up at 12 weeks. On every follow up clinical and radiological evaluations were done to assess progress of function and evidence of union. In our study all fracture united at an average of 7.3 weeks with maximum time to union being 14 weeks in two patients. The K-wires were removed only after the full union. The cases were followed up for 12 months and were graded according to the system described by Price et al.All the relevant information were entered into the microsoft word, statistical package for social services (SPSS) version 19, Microsoft Excel and analyzed.

\section{RESULTS}

A total of 32 patients enrolled in the study. Gender wise male is to female ratio was $3: 1$. Average age of study subjects was 10.41 years for males and 10.21 years for females, range 5-15 years .Fall from tree was the commonest cause of fracture followed by ground level fall and road traffic accident. Out of 32 patients 28 had excellent ( $87.5 \%), 3$ had good (9.3\%) and 1 had fair (3.1\%) results according to the Price et al grading system.

\section{DISCUSSION}

Forearm shaft fractures are the common traumatic injuries in children.Its standard treatment is usually conservative by close reduction and POP cast immobilization ${ }^{16}$, but because of higher incidence of redisplacement, compartment syndrome, prolonged immobilization and also the idea of moving a fractured limb soon after injury, there has been shift of trend from managing these fractures by close reduction and POP cast immobilization to open/close reduction and internal fixation with intramedullary or extramedullary devices ${ }^{17}$. Multiple techniques are available to immobilize the fragments after surgery including plates and screws, intramedullary rods and external fixation. ${ }^{18}$ With advent of image intensification, close reduction and percutaneous intramedullary fixation came out to be attractive alternative in the management of unstable paediatric forearm fractures ${ }^{19}$.

The present trend in treatment of displaced diaphyseal forearm fracture in children is closed reduction and stabilization with elastic intramedullary nails ${ }^{20.21,22}$. Usually the portal of entry of nail adopted by various authors is through distal end of radius and proximal end of ulna ${ }^{23,24,25}$. But this approach is frought with complications like injury to physis of lower end of radius and upper end of ulna and restriction of wrist and elbow movements in $20 \%$ to $30 \%$ cases. To avoid these complications the portal of entry made through distal metaphysis of radius and ulna avoiding the physis is thought to be harmless ${ }^{26,27,28}$. Our Study was designed to avoid complications due to injury of lower radial and upper ulnar physis and impairment of functions of wrist and elbow by fixation of forearm fractures with $316 \mathrm{~L}$ stainless steel wires, which were cheaper, easily available and can be passed with comfort across the diaphyseal forearm bones fracture through retrograde approach.

The incidence of nail prominence in the present study was minimal since the nail was well covered underneath soft tissues after closing the wound. However six (12\%) patients who had nail prominence, they developed superficial bursitis and the nail was removed at 4 months as the fracture had united. During nail removal the inflammed bursa was excised. These patients had no complain in the subsequent follow-ups. 


\begin{tabular}{|c|c|c|c|c|c|}
\hline \multirow{2}{*}{ Sex } & \multicolumn{2}{|c|}{ Age in years } & \multirow{2}{*}{ Total } & $\begin{array}{c}\text { Average age at } \\
\text { surgery }\end{array}$ & Percentage \\
\cline { 2 - 3 } & $\mathbf{0 5 - \mathbf { 0 9 }}$ & $\mathbf{1 0 - 1 5}$ & & 10.41 & $72 \%$ \\
\hline Male & 10 & 10 & 20 & 10.21 & $28 \%$ \\
\hline Female & 4 & 8 & 12 & & \\
\hline
\end{tabular}

Table II : Distribution of patients according to age and sex

\begin{tabular}{|c|c|c|c|c|}
\hline \multirow{2}{*}{ Mode of injury } & \multicolumn{2}{|c|}{ Age group in years } & \multirow{2}{*}{ Total } & \multirow{2}{*}{ Percentage } \\
\cline { 2 - 3 } & $\mathbf{0 5 - \mathbf { 0 9 }}$ & $\mathbf{1 0 - 1 5}$ & 18 & $56.25 \%$ \\
\hline Fall from tree & 8 & 10 & 6 & $18.75 \%$ \\
\hline Ground level fall & 4 & 2 & 6 & $18.75 \%$ \\
\hline Fall from bicycle & 3 & 3 & 2 & $6.25 \%$ \\
\hline RTA & 0 & 2 & & \\
\hline
\end{tabular}

Table III : Age group distribution in relation to mode of injury

\begin{tabular}{|c|c|c|}
\hline Outcome & Number of patients & Percentage \\
\hline Excellent & 28 & $87.5 \%$ \\
\hline Good & 3 & $9.3 \%$ \\
\hline Fair & 1 & $3.1 \%$ \\
\hline Poor & 0 & $0 \%$ \\
\hline
\end{tabular}

Table IV : Distribution of functional outcome in relation to the Grading system of Price et al. ${ }^{47}$

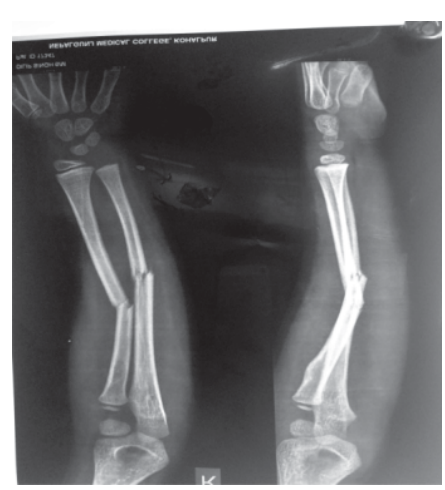

Figure 1: $X$-ray $A / P$ and Lateral view of forearm after injury
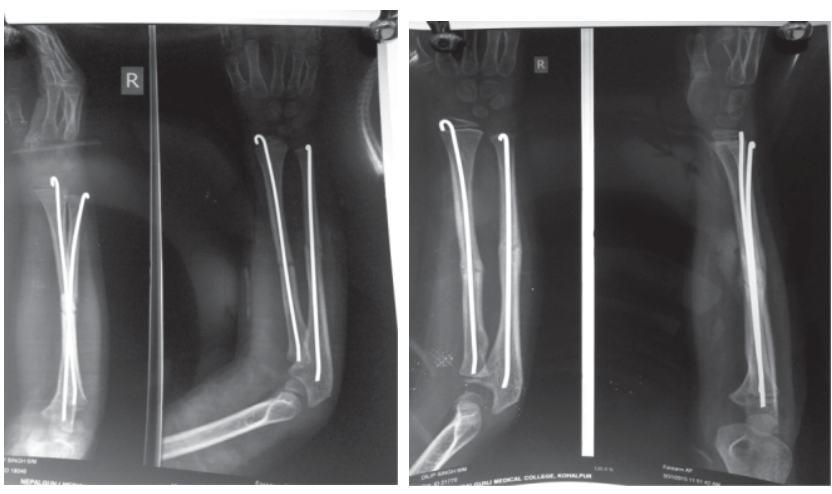

Figure 2: Follow up X-ray at Figure 3: Follow up X-ray at 4 weeks
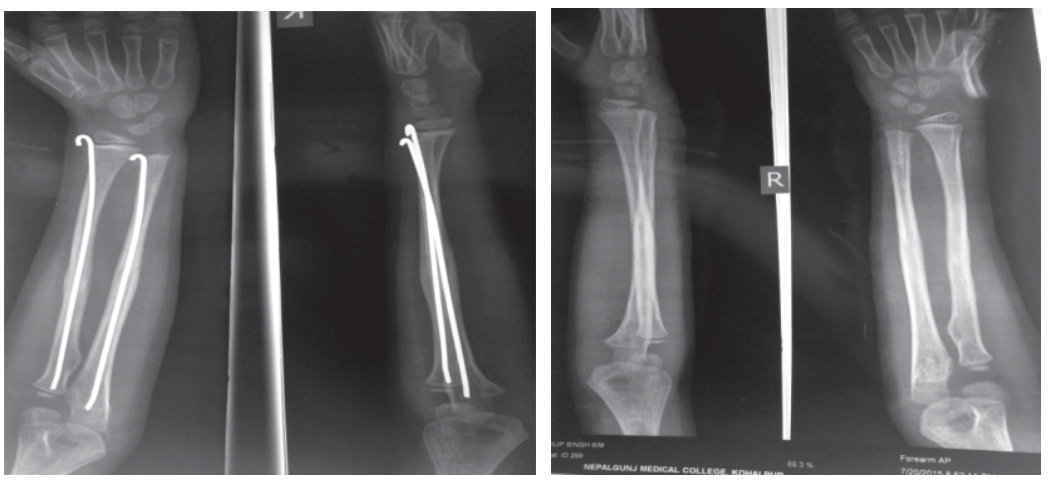

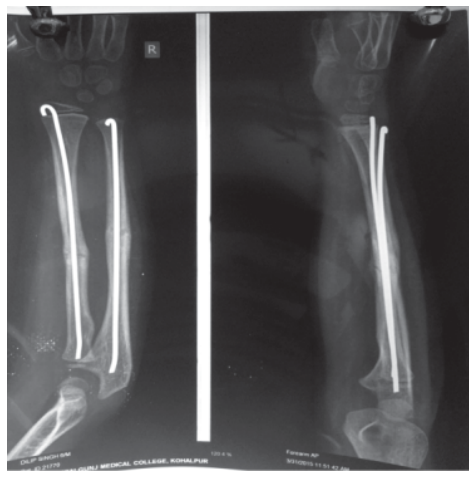

Figure 4: Follow up X-ray at 12 weeks

Figure 5: X-ray after removal of implants 
Two (4\%) patients suffered from a transient loss of sensibility of the thumb post-operatively which were probably caused by irritation of the superficial branch of the radial nerve during insertion of the radial intramedullary nail at the portal of entry. But the complaints gradually improved by the third month.

There were two (4\%) cases of delayed union, both with Grade I open fractures. One was 12 and the other was 14 years old. Their fractures united by 14 weeks without any intervention.

The stainless steel intramedullary nails are as effective as titanium nails for the treatment of displaced diaphyseal forearm bones fracture in children. There is no difference in union rates, complications and functional outcomes between stainless steel and titanium nails used for stabilization of fractures. Moreover stainless steel nail is more cost effective when compared to the titanium alloy.

In the present study, all the fractures were stabilized by closed reduction and intramedullary K-wire fixation. There were not significant intraoperative complications. The child after surgery was discharged after an average hospital stay of $4.04 \pm .832$ days, as such for school going children there was not much school hour loss.

\section{CONCLUSION}

Intramedullary elastic nailing is minimally invasive and less technically demanding. The patients usually require a hospital stay of an average of three to four days, unless there are complications like compartment syndrome and wound infection. It prevents the loss of school hours for the children as well as reduces the economical burden off the family.

\section{REFERENCES}

1. Bucholz RW, HeckmanJD, Brown CC. Injuries to the Shafts of the Radius and Ulna. Rockwood \& Wilkins' Fractures in Children, 6th Edition: Lippincott Williams \& Wilkins, 2006; p:402-37.

2. Chung KC, Spilson SV. The frequency and epidemiology of hand and forearm fractures in the United States. J Hand Surg [Am] 2001; 26:908-15.

3. Huber RI, Keller HW, Huber PM et al. Flexible intramedullary nailing as fracture treatment in children. J PediatrOrthop 1996; 16:602-5.

4. Kucukkaya M, Kabukcuoglu Y, Tezer M, et al. The application of open intramedullary fixation in the treatment of pediatric radial and ulnar shaft fractures. J Orthop Trauma 2002; 16(5):340-4.

5. Mann DC, Rajmaira S: distribution of physeal and non physeal fractures in 2,650 long bone fractures in childrenaged $0-16$ years. J Pediatr Orthop 1990, 10:713.

6. Worlock P, Stower: Fracture pattern in Nottingham children. J Pediatr Orthop 1986:656.
7. Sinikumpu JJ, Serlo W: Forearm shaft fractures in children. Acta Univ. Oul. D 1221, 2013.

8. Mehlman CT, Wall EJ. Injuries to the shafts of the radius and ulna.In:Beaty JH, Kasser JR, editors Rockwood and Wilkins' fractures in children 7th ed Philadelphia:Lippincott Williams \& Wilkins:2010 p347-402.

9. Jones $\mathrm{K}$, Weiner DS: The management of forearm fractures in children: A plea for conservatism.J Pediatr Orthop 1999;19:811.

10. Price $\mathrm{CT}$, Mencio GA. Injuries to the shafts of the radius and ulna. In: Beaty JH, Kasser JR, eds. Rockwood \& Wilkins fractures in children, 5th ed. Philadelphia: Lippincott Williams \& Wilkins, 2001:452-60.

11. Wright J, Rang M. Internal fixation for forearm fractures in children. Techniques Orthop 1989; 4:44 - 7.

12. Verstreken L, Delronge G, Lamoureux J: Shaft forearm fractures in children: Intramedullary nailing with immediate motion: A preliminary report. J Pediatr Orthop 1988;8:450.

13. Ali AM, Abdelaziz M, Lakanney MR. Intramedullary nailing for diaphyseal forearm fractures in children after failed conservative treatment. Journal of Orthopaedic Surgery 2010; 18(3):328-31.

14. Celebi L, Muratli HH, Dogan O et al. The results of intramedullary nailing in children who developed redisplacement during cast treatment of both-bone forearm fractures. Acta Orthop Traumatol Turc 2007; 41(3):175-182.

15. Ge YH, Wang ZG, Cai HQ et. al. Pre-bent elastic stable intramedullary nail fixation for distal radial shaft fractures in children. Orthopaedic Surgery 2010; 2(3): 229-33.

16. Jones $K$, Weiner DS: The management of forearm fractures in children: A plea for conservatism.J Pediatr Orthop 1999;19:811.

17. Goyal M, Garg RS, Kapila R. Esin- a gold standard for the management of forearm fractures in children; $\mathrm{Pb}$ Journal of Orthopaedics Vol-XIV, No.1, 2013.

18. Wilkins K: Fractures of the radius and ulnar shafts. In: KE W, ed. Operative Management of Upper Extremity Fractures in Children, Rosemont, IL: Americn Academy of Orthopaedic Surgeons; 1994.

19. Van der Reis WL, Otsuka NY, Moroz P et al. Intramedullary nailing versus plate fixation for unstable forearm fractures in children. $J$ Pediatr Orthop 1998; 18: 9-13

20. Kang SN, Mangwani J, Ramachandran $M$ et al. Elastic intramedullary nailing of paediatric fractures of the forearm: a decade ofexperience in a teaching hospital in the United Kingdom. J Bone Joint Surg Br. 2011; 93:262-5.

21. Altay M, Aktekin CN, Ozkurt B et al. Intramedullary wire fixation for unstable forearm fractures in children; Injury, Int. J. Care Injured (2006) 37, 966-73.

22. Richter D, Ostermann PA, Ekkernkamp A et al. Elastic intramedullary nailing: a minimally invasive concept in the treatment of unstable forearm fractures in children. J Pediatr 
Orthop 1998; 18(4):457-61.

23. Ahmed I, Asrar Z, Durani Z et al. Intramedullary kirschner wire fixation of unstable radius- ulna fractures in children; Pakistan journal of surgery 2007;23(3).

24. Reinhardt KR, Feldman DS, Green DW et al. Comparison of intramedullary nailing. to plating for both-bone forearm fractures in older children. J Pediatr Orthop. 2008; 28:403-9.

25. Shah AS, Lesniak BP, Wolter TD et al. Stabilization of adolescent bothbone forearm fractures: a comparison of intramedullary nailing versus open reduction and internal fixation. J Orthop Trauma. 2010; 24:440-7.

26. Lee $S$, Nicol RO, Stott NS. Intramedullary fixation for paediatric unstable forearm fractures. Clin Orthop 2002; 402: 245- 50.

27. Yuan PS, Pring ME, Gaynor TP et al. Compartment syndrome following intramedullary fixation of pediatric forearm fractures. Journal of Pediatric Orthopaedics July/August 2004; 24(4);370-5.

28. Ali AM, Abdelaziz M, Lakanney MR. Intramedullary nailing for diaphyseal forearm fractures in children after failed conservative treatment. Journal of Orthopaedic Surgery 2010; 18(3):328-31. 